\title{
Effects of dexmedetomidine on oxidative stress and inflammatory response in lungs during mechanical ventilation in COPD rats
}

\author{
PENGCHENG LI ${ }^{1,2}, \mathrm{JING} \mathrm{HAN}^{3}, \mathrm{DAN}^{2} \mathrm{ZHANG}^{4}, \mathrm{SHU} \mathrm{CAO}^{4}$ and $\mathrm{CHUNYU} \mathrm{SU}^{4}$ \\ ${ }^{1}$ Department of Anesthesiology, The First Hospital of Qiqihar; ${ }^{2}$ Department of Anesthesiology, Affiliated Qiqihar Hospital, \\ Southern Medical University; ${ }^{3}$ Department of Anesthesiology, General Hospital of Qiqihar Jianhua Factory; \\ ${ }^{4}$ Department of Anesthesiology, Qiqihar Hospital of Traditional Chinese Medicine, \\ Qiqihar, Heilongjiang 161000, P.R. China
}

Received September 13, 2019; Accepted November 8, 2019

DOI: $10.3892 / \mathrm{etm} .2019 .8341$

\begin{abstract}
Effects of dexmedetomidine (Dex) on oxidative stress and inflammatory response in lungs during mechanical ventilation in chronic obstructive pulmonary disease (COPD) rats were investigated. Eleven out of $38 \mathrm{SD}$ rats were randomly selected as the blank control group, and the other 27 rats were subjected to modeling. After the modeling, 11 rats in the blank control group and 11 rats randomly selected from the model group received non-invasive test for lung function. Three rats from the blank control group and 3 rats from the model group were selected for hematoxylin and eosin (HE) staining to confirm successful modeling, and the other 24 rats were randomly divided into 3 groups, 8 rats in each group, including model control, Dex low-dose and Dex high-dose group. A COPD rat model was established by passive cigarette smoking and intratracheal instillation of lipopolysaccharide. Each group underwent mechanical ventilation for $2 \mathrm{~h}$. The Dex low-dose group and Dex high-dose group were intravenously administered at $1.0 \mu \mathrm{g} / \mathrm{kg} / \mathrm{h}$ and $5.0 \mu \mathrm{g} / \mathrm{kg} / \mathrm{h}$ of Dex, and the other two groups received intravenous drip of the same amount of normal saline. Blood gas analysis was performed to calculate carbon dioxide partial pressure $\left(\mathrm{PaCO}_{2}\right)$, oxygen partial pressure $\left(\mathrm{PaO}_{2}\right)$ and blood $\mathrm{pH}$. HE staining was performed to analyze pulmonary pathological features of COPD rat model. Serum inflammatory factors interleukin- 8 (IL-8), tumor necrosis factor-alpha (TNF- $\alpha$ ) and malondialdehyde (MDA) were detected by ELISA, and the levels of antioxidant enzymes superoxide dismutase 2 (SOD2) and catalase were analyzed by western blot analysis. After 28 days of modeling, TV, PEF, FEV0.3 and FEV0.3/FVC decreased
\end{abstract}

Correspondence to: Dr Chunyu Su, Department of Anesthesiology, Qiqihar Hospital of Traditional Chinese Medicine, 48 Ping'an South Street, Qiqihar, Heilongjiang 161000, P.R. China

E-mail: suchunyu0301@126.com

Key words: chronic obstructive pulmonary disease, mechanical ventilation, dexmedetomidine, oxidative stress, inflammatory response significantly in the COPD model group. HE staining showed that in the model group, the alveolar cells became larger, the alveolar wall became thinner, and some alveolar walls were even broken. The lung lobule showed obvious cell degeneration, necrosis and shedding, and the interstitial inflammatory cell infiltration, suggesting that the COPD rat model was successfully established. After $2 \mathrm{~h}$ of mechanical ventilation and Dex intravenous infusion, $\mathrm{PaCO}_{2}$ decreased, $\mathrm{PaO}_{2}$ increased, and blood $\mathrm{pH}$ value increased $(\mathrm{p}<0.05)$. Inflammatory factors IL-8 and TNF- $\alpha$ decreased $(\mathrm{p}<0.05)$. Oxidative stress index MDA also decreased $(\mathrm{p}<0.05)$, antioxidant enzymes SOD2 and catalase increased $(\mathrm{p}<0.05)$. Dexmedetomidine can improve the oxidative stress response during mechanical ventilation in rats with COPD, and can reduce the inflammation of lung tissue, thus protecting the lung tissue of COPD rats.

\section{Introduction}

Chronic obstructive pulmonary disease (COPD) is a chronic respiratory disease characterized by airflow limitation, which is irreversible with a progressive decline in lung function. The prevalence of COPD of people aged over 30 years in Asia is $6.3 \%$ (1), and the increasing environmental pollution and smoking lead to its increasing incidence, which brings a heavy economic burden to patients and their families (2). The pathogenesis of COPD has not yet been elucidated. The present research suggests that its pathogenesis is related to inflammation, oxidative stress and protease. These factors act on the lungs, leading to lung lesions (3-5).

COPD can seriously damage the structure of the respiratory tract and cause repeated pulmonary infections. Coupled with chronic hypoxia and irreversible airflow limitation in COPD patients, these factors can seriously impair patient's respiratory function and even lead to respiratory failure (6). As an important auxiliary ventilation measure, mechanical ventilation plays an important role in the acute exacerbation and general anesthesia of COPD patients (7). As an invasive therapy, mechanical ventilation provides oxygen to the body. However, at the same time, it causes pain, induces multiple stress reactions and aggravates patient's lung injury (8). Dexmedetomidine is a new type of highly selective $\alpha 2$ adrenergic receptor agonist widely used in intensive care and 
anesthesiology, and dexmedetomidine (Dex) can produce calming, analgesic, hypnosis, anti-sympathetic effects by inhibiting the release of catecholamines in the plasma (9). In recent years, a large number of studies (10-12) have shown that Dex has protective effects on various organs, and can improve lung function and reduce the impact on lung hemodynamics. However, regarding its mechanical ventilation to patients with COPD, the mechanism remains unclear. Therefore, this study used passive smoking and intratracheal instillation of lipopolysaccharide to establish a rat COPD model, and explored the effects of different doses of Dex on lung oxidative stress and inflammatory response in mechanical ventilation of COPD rats.

\section{Materials and methods}

Materials and reagents. The experimental SPF grade SD rats (8 weeks old, male, weighing 200-250 g) were purchased from the Animal Experimental Center of Henan Province, and the experiment was carried out after 1 week of adaptive feeding. Superoxide dismutase 2 (SOD2) (cat. no. 13194), catalase (cat. no. 14097), and monoclonal antibody were purchased from CST. Internal reference $\beta$-actin (cat. no. 20536-1-AP) and horseradish peroxidase (HRP) labeled secondary antibody (cat. no. SA00001-2) were purchased from Proteintech. Interleukin-8 (IL-8) (cat. no. HM10222), tumor necrosis factoralpha (TNF- $\alpha$ ) (cat. no. HM10001-S), malondialdehyde (MDA) (cat. no. HM10250), and enzyme-linked immunosorbent assay (ELISA) kit were from Bio-swamp. Hematoxylin and eosin (HE) staining kit and the RIPA lysate were purchased from Biotime Biological Co., Ltd. Dexmedetomidine hydrochloride injection ( $2 \mathrm{ml}: 200 \mu \mathrm{g}$ ) was purchased from Jiangsu Hengrui Pharmaceutical Co., Ltd.

All animal experiments were in accordance with the ethical standards for laboratory animals and approved by the Ethics Committee of the First Hospital of Qiqihar (Qiqihar, China).

Establishment of a COPD rat model. Eleven of the $38 \mathrm{SD}$ rats were randomly selected as the blank control group. The other rats were used to establish COPD rat model according to the method in the literature (13), by passive cigarette smoking and intratracheal instillation of lipopolysaccharide. On the first day and the 14th day, $200 \mu \mathrm{l}$ of $1 \mathrm{~g} / \mathrm{l}$ lipopolysaccharid was injected into the trachea. From the 2nd to the 28th day (except the 14th day), all rats were placed in a sealed $1 \mathrm{~m}^{3}$ smoke chamber. Pressure was controlled at a standard atmospheric pressure $(101.325 \mathrm{kPa})$, and the cigarette inhalation was continued for 30 min every day. Blank control group was not performed with any intervention. All rats had free access to food and water, and the animal room had natural light, a temperature of $20-25^{\circ} \mathrm{C}$, and a relative humidity of $45-50 \%$. The general condition of the survival of the rats was observed daily. On the 29th day, 11 rats in the blank control group and 11 rats randomly selected from the model group received non-invasive test for lung function. Three rats from the blank control and 3 rats from the model were randomly selected from the model group. After blood was taken, lung tissues were taken for pathological examination to determine whether the modeling was successful.
Non-invasive lung function test. Twenty-two rats were placed in the EMKA small animal non-invasive pulmonary function monitoring system, and calm breathing was recorded first. Then the rat tidal volume (TV), peak expiratory flow rate (PEF), 50\% lung vitality maximum expiratory flow (PE50), $0.3 \mathrm{sec}$ forced expiratory volume (FEV0.3), and $0.3 \mathrm{sec}$ forced expiratory volume to forced vital capacity ratio (FEV0.3/FVC) were recorded. The averages of 3 measurements per parameter were taken.

Lung histopathology test. After the lung tissue was fixed by 4\% paraformaldehyde, it was dehydrated in 50, 70, 80, 95, 100 and $100 \%$ alcohol, for 20 min each time. Then the dehydrated tissue was placed in: Ethanol + xylene (1:1) for $2 \mathrm{~h}$, xylene I and II for 10 min each, then placed in xylene + paraffin (1:1) for $2 \mathrm{~h}$, paraffin I (1 h), paraffin II (2 h) to immerse. After embedding in an ice box, $4 \mu \mathrm{m}$ paraffin slices were made, which were then dewaxed with xylene and gradient alcohol, and stained with hematoxylin and eosin for observation under a microscope.

Experimental grouping and administration. The remaining 24 model rats were randomly divided into 3 groups, 8 in each group, which were the model control group, Dex low-dose group, and Dex high-dose group. All rats fasted for $12 \mathrm{~h}$ before anesthesia and fasted of liquid for $4 \mathrm{~h}$. After weighing, they were anesthetized with $10 \%$ chloral hydrate at a dose of $0.3 \mathrm{ml} / 100 \mathrm{~g}$. The rats were fixed on a table covered with an electric blanket and placed in a supine position. The temperature of the rat was monitored by a rectal temperature probe and maintained at about $37^{\circ} \mathrm{C}$. The tail of the rat was disinfected with vital iodine, then a puncture was performed. The infusion pump was used to infuse $2 \mathrm{ml} / \mathrm{kg} / \mathrm{h}$ normal saline, and the tail vein was injected with $1 \mathrm{mg} / \mathrm{kg}$ vecuronium to inhibit spontaneous breathing in rats. Hydroxyethyl starch $(4-8 \mathrm{ml} / \mathrm{kg} / \mathrm{h})$ was intermittently infused to maintain blood pressure stability. The neck was disinfected, and the towel was placed to perform tracheostomy. The tracheal tube was inserted and fixed. The mechanical ventilation parameters were set as: mechanical ventilation tidal volume: VT: $8 \mathrm{ml} / \mathrm{kg}$, ventilation frequency: 60-80 times/min, maintaining $\mathrm{PErCO}_{2}$ at $35-45 \mathrm{mmHg}$, suction/hit ratio: 1:3, and the inspired oxygen concentration was set at $45 \%$. The mechanical ventilation of all groups last $2 \mathrm{~h}$. In the Dex low-dose group, Dex $1.0 \mu \mathrm{g} / \mathrm{kg} / \mathrm{h}$ continuous infusion was given during mechanical ventilation, and Dex high-dose group was given Dex $5.0 \mu \mathrm{g} / \mathrm{kg} / \mathrm{h}$ continuous infusion. Blank control and model control group were given the same amount of normal saline infusion for $2 \mathrm{~h}$. After mechanical ventilation, the chest was opened to obtain the lungs. One part was placed in $4 \%$ paraformaldehyde and fixed, the other part was stored at $-80^{\circ} \mathrm{C}$ for later use.

Blood gas analysis. Arterial blood was taken by carotid artery puncture before and after mechanical ventilation in rats, and some blood was taken for blood gas analysis using ABL800 blood gas analyzer (Dadiometer, Denmark), including partial pressure of carbon dioxide $\left(\mathrm{PaCO}_{2}\right)$, partial pressure of oxygen $\left(\mathrm{PaO}_{2}\right)$ and $\mathrm{PH}$ value.

ELISA test. The remaining blood in the blood gas analysis was centrifuged $\left(12,000 \mathrm{xg}\right.$ at $4^{\circ} \mathrm{C}$ for $\left.15 \mathrm{~min}\right)$ and the serum 
Table I. Weight gain of SD rats before and after modeling.

\begin{tabular}{lccc}
\hline Groups & $\begin{array}{c}\text { Before } \\
\text { modeling }\end{array}$ & $\begin{array}{c}\text { After } \\
\text { modeling }\end{array}$ & $\begin{array}{c}\text { Weight } \\
\text { gain }\end{array}$ \\
\hline Blank control & $228.63 \pm 22.58$ & $408.13 \pm 20.52$ & $179.5 \pm 11.19$ \\
COPD model & $228.16 \pm 27.33$ & $383.96 \pm 29.0$ & $155.8 \pm 20.16^{\text {a }}$ \\
\hline
\end{tabular}

COPD, chronic obstructive pulmonary disease. ${ }^{\mathrm{a}}$ Compared with blank control group, $\mathrm{p}<0.05$.

was stored at a low temperature. ELISA kit was equilibrated to room temperature, and the standard solution was diluted in accordance with the specifications. Six concentration gradients were set, and $50 \mu \mathrm{l}$ of different concentration of standards was added to each well. Two wells, blank wells and sample wells, were set for each. A total of $40 \mu \mathrm{l}$ of the sample was added to the sample well, and then $10 \mu$ l of biotin-labeled IL- 8 , TNF- $\alpha$, and MDA antibodies were added, respectively, to the bottom of the well, without touching the well wall. A total of $50 \mu \mathrm{l}$ of the enzyme labeling reagent was added to each well except the blank wells, and then incubated at $37^{\circ} \mathrm{C}$ for $30 \mathrm{~min}$ after the plate was closed. The liquid was discarded and dried. A total of $200 \mu \mathrm{l}$ of washing solution was added per well and discarded after standing for $30 \mathrm{sec}$, and repeated 5 times. After patted dry, each well was added with $50 \mu \mathrm{l}$ of chromogenic reagents $\mathrm{A}$ and $\mathrm{B}$, respectively, the chromogenic reaction was performed in the dark at $37^{\circ} \mathrm{C}$ for $10 \mathrm{~min}$, and $50 \mu \mathrm{l}$ of stop solution was added to terminate the reaction. The blank well was zeroed, the absorbance of each well was measured at $450 \mathrm{~nm}$ wavelength. The data were entered into the computer to make a standard curve and the regression equation, then the content in the sample well was determined.

Detection of SOD2 and catalase in lung tissue. Lung tissue (30 mg) was added with $300 \mu \mathrm{l}$ lysate and grinded on ice, standing for $30 \mathrm{~min}$ to make it fully lysed, then centrifuged at $4^{\circ} \mathrm{C}$ and at $12,000 \times \mathrm{g}$ for $15 \mathrm{~min}$. Supernatant $(10 \mu \mathrm{l})$ was obtained to quantify BCA protein. The remaining supernatant was added with $5 x$ sample buffer by $4: 1$ volume, placed in a $100^{\circ} \mathrm{C}$ water bath for $10 \mathrm{~min}$, and the sample was loaded according to equal total protein amount. Electrophoresis was carried out with 5\% laminating gel and 10\% separating gel at $80 \mathrm{~V}$ voltage until bromophenol blue entered separating the gel, the voltage was changed to $120 \mathrm{~V}$ until the target strip was separated. Then the protein was transferred to the PVDF membrane by wet transfer method at $275 \mathrm{~mA}$ for $80 \mathrm{~min}$, and blocked with $5 \%$ milk at room temperature for $2 \mathrm{~h}$. Then diluted $(1: 1,000)$ SOD2, catalase and $\beta$-actin antibodies were added and incubated overnight at $4^{\circ} \mathrm{C}$. After washing, $2 \%$ milk-configured secondary antibody $(1: 10,000)$ was added for $1 \mathrm{~h}$ at room temperature, and developed. Image $\mathrm{J}$ was used for analyzing the band gray value, $\beta$-actin as internal reference. The protein relative expression amount was the ratio of the gray value of the target protein to the gray value of $\beta$-actin.

Statistical analysis. The results are expressed as mean \pm standard deviation. The data were analyzed by SPSS 20 (IBM Corp.,
Table II. Pulmonary function indicators of SD rats after modeling.

\begin{tabular}{lcc}
\hline & \multicolumn{2}{c}{ Groups } \\
\cline { 2 - 3 } & $\begin{array}{c}\text { Blank control } \\
(\mathrm{n}=11)\end{array}$ & $\begin{array}{c}\text { COPD model } \\
(\mathrm{n}=11)\end{array}$ \\
\hline Indicators & $2.73 \pm 0.32$ & $1.47 \pm 0.25^{\mathrm{a}}$ \\
$\mathrm{TV}(\mathrm{ml})$ & $37.15 \pm 1.83$ & $16.38 \pm 2.13^{\mathrm{a}}$ \\
$\mathrm{PEF}(\mathrm{ml} / \mathrm{s})$ & $1.79 \pm 0.20$ & $1.35 \pm 0.22^{\mathrm{a}}$ \\
EP50 $(\mathrm{ml} / \mathrm{s})$ & $4.42 \pm 0.33$ & $2.33 \pm 0.32^{\mathrm{a}}$ \\
FEV0.3 $(\mathrm{ml})$ & $87.61 \pm 4.41$ & $64.49 \pm 4.30^{\mathrm{a}}$ \\
FEV0.3/FVC $(\%)$ &
\end{tabular}

TV, tidal volume; PEF, peak expiratory flow rate; FEV, forced expira-

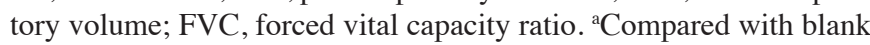
control group, $\mathrm{P}<0.05$.

Armonk, NY, USA). t-test was used for comparison between two groups. One-way ANOVA was used for comparison of multi groups. LSD test was used if the variance was equal. If the variance was unequal, Dunnett's t-test was used. The statistical difference was set at $\mathrm{p}<0.05$, and each experiment was repeated at least three times.

\section{Results}

General survival of rats. In the normal control group, all rats had good mental state, flexible response, normal skin gloss, normal diet, normal breathing, and normal weight gain. In the model group, rats developed slowly and were in poor spirit. The amount of activity was reduced, and the response to external stimuli was slow, skin was yellow, gloss was poor, appetite was weak, body was thin, and the weight gain was slow (Table I). There were respiratory diseases such as cough and wheezing.

Lung histopathological changes. Compared with the blank control group, the TV, PEF, FEV0.3, and FEV0.3/FVC of the COPD model group were significantly decreased (Table II), suggesting airflow limitation in the COPD model group.

Gross view of rat lung tissue. Lung tissue volume of normal control group was basically normal, surface was smooth, elasticity was good and whole lung was light red. In model group, lung tissue volume of the rat was significantly increased, and surface was rough with a large amount of black particulate matter; the edges became dull, the elasticity was reduced, and the lungs were dark purple-red. HE staining showed that in normal control group, lung lobule structure of the rat lung tissue was normal; the cells had no obvious congestion or edema, no degeneration or necrosis, no or only a small amount of inflammatory cell infiltration; the alveolar of the model group became large, the alveolar wall became thinner; some alveolar walls were broken, and the cell lobule showed obvious cell degeneration, necrosis and shedding; a large amount of inflammatory cell infiltration appeared in the interstitial space, suggesting that the COPD rat model was successfully established (Fig. 1). 


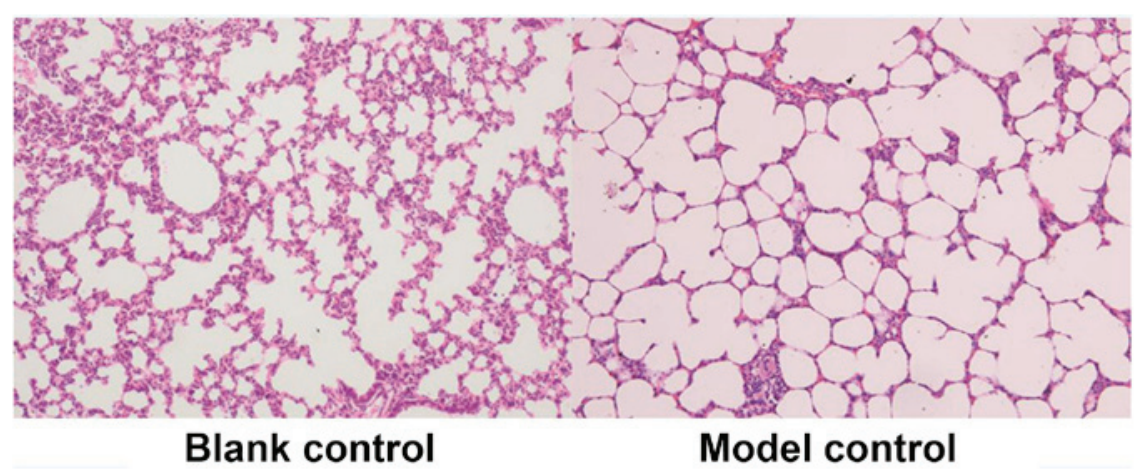

Figure 1. HE staining of lung tissue in blank control and model control group (40x). HE, hematoxylin and eosin.

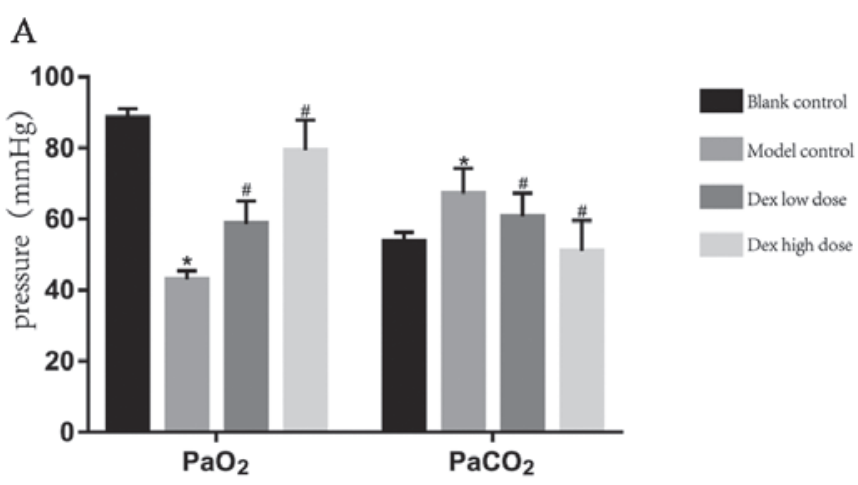

B

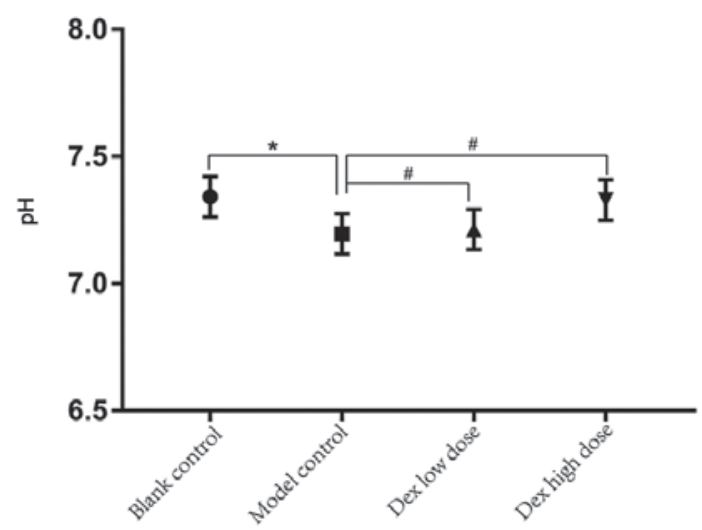

Figure 2. Blood gas analysis: (A) Dex can reduce $\mathrm{PaCO}_{2}$ in the blood of COPD model rats and improve $\mathrm{PaO}_{2}$. (B) Different doses of dex can reverse acidosis in COPD rats. "p $<0.05$, compared with the blank control group $" \mathrm{p}<0.05$, compared with the model control group. Dex, dexmedetomidine; $\mathrm{PaCO}_{2}$, carbon dioxide partial pressure; COPD, chronic obstructive pulmonary disease; $\mathrm{PaO}_{2}$, oxygen partial pressure. $\mathrm{n}=8$.

Blood gas analysis. Blood gas analysis showed (Fig. 2) that compared with the blank control group, the $\mathrm{PaO}_{2}$ of the model control group decreased significantly, and the $\mathrm{PaCO}_{2}$ increased significantly, the blood $\mathrm{pH}$ value decreased $(\mathrm{p}<0.05)$; while after treatment with different dose of Dex during mechanical ventilation, $\mathrm{PaO}_{2}$ increased and $\mathrm{PaCO}_{2}$ decreased significantly. This effect was significantly increased with increasing dose of Dex, and blood $\mathrm{pH}$ returned to normal levels (Fig. 2B).

Effect of Dex on inflammatory factors and oxidative stress in COPD rats. As shown in Fig. 3, levels of inflammatory factors
IL-8 and TNF- $\alpha$ were significantly increased in COPD rats $(\mathrm{p}<0.05)$, and the contents of MDA were also significantly increased $(\mathrm{p}<0.05)$. After treatment with low dose Dex and high dose Dex, serum IL-8, TNF- $\alpha$ and MDA in COPD model rats were significantly decreased $(\mathrm{p}<0.05)$, and decreased with the increase of Dex dose.

Western blot analysis of SOD2 and catalase. Compared with the blank control group, SOD2 and catalase were significantly decreased in the lung tissue of the model control group $(\mathrm{p}<0.05)$. After low dose Dex and high dose Dex infusion, SOD2 and catalase were significantly increased $(\mathrm{p}<0.05)$ in a dose-dependent manner (Fig. 4).

\section{Discussion}

Smoking is not only the leading cause of death in preventable diseases, but is also the most important risk factor for COPD. A large amount of particulate matter and harmful gases such as IL- 8 and TNF- $\alpha$ in cigarette smoke can cause and aggravate oxidative stress and inflammatory reactions in the lungs. These inflammatory mediators can destroy the elastic fibers of the lungs and airways, causing decreased compliance, increased airway secretions, and limited irreversibility of the respiratory tract (14). LPS is an antigen on the cell wall surface of Gram-negative bacteria, which can promote the activation of inflammatory cells and release a large number of inflammatory factors (15). The administration of a certain dose of lipopolysaccharide can induce chronic inflammation of the airway and alter lung function (16). Although a previous study showed that Dex provided clinically relevant benefits for patients with moderate COPD who underwent lung cancer surgery, there was no direct evidence that Dex had an effect on mechanical ventilation in patients with COPD. In this study, we established a COPD rat model to investigate the effects of Dex on oxidative stress and inflammatory response, providing a theoretical basis for the application of Dex and mechanical ventilation in patients with clinical COPD.

In this study, a cigarette smoke assay + multiple intratracheal instillation of LPS was used to establish a COPD rat model. After 28 days of modeling, the rats showed loss of appetite, body weight loss, slow weight gain, and cough, wheezing and other respiratory system diseases. After the HE 


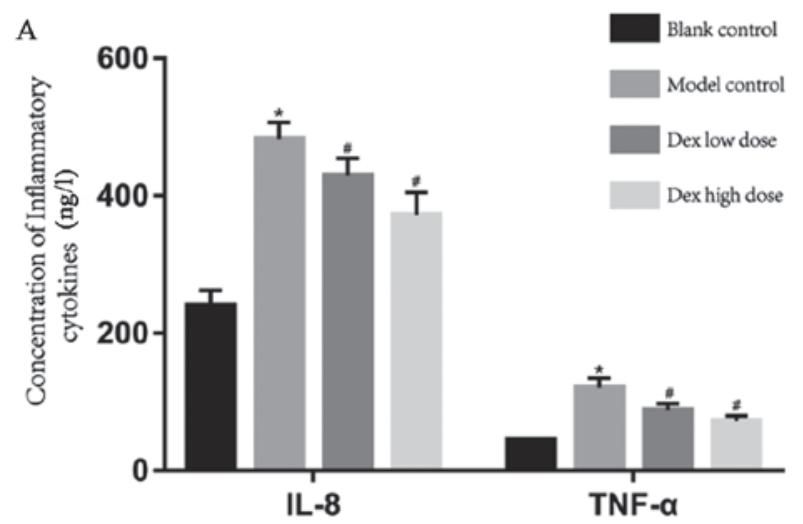

B

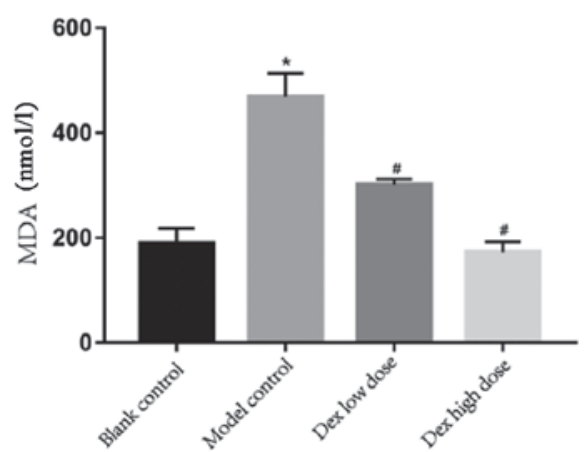

Figure 3. ELISA analysis of inflammatory factors and MDA in rat blood. (A) Different doses of dex reduce serum inflammatory factors IL- 8 and TNF- $\alpha$. (B) Different doses of dex reduce serum MDA. "p $<0.05$, compared with the blank control group; ${ }^{\prime} \mathrm{p}<0.05$, compared with the model control group. Dex, dexmedetomidine; IL-8, interleukin-8; MDA, malondialdehyde; TNF- $\alpha$, tumor necrosis factor alpha. (n=8).

A
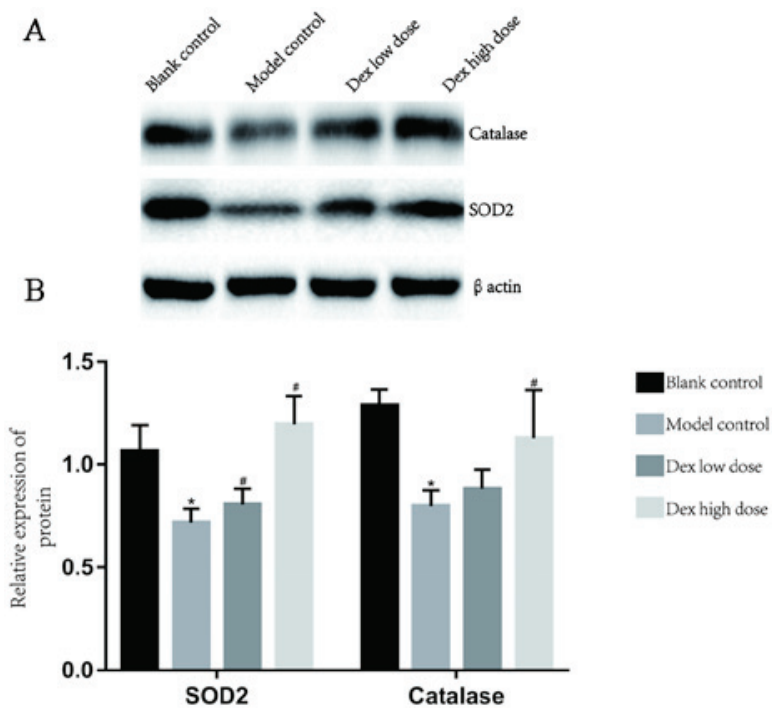

Figure 4. Western blot analysis of SOD2 and catalase in lung tissue. (A) The western blot bands of Catalase and SOD2. (B) The histogram of SOD2 and Catalase. "p $<0.05$, compared with the blank control group; ${ }^{\#} \mathrm{p}<0.05$ compared with the model control group. Dex, dexmedetomidine; SOD2, superoxide dismutase 2. $(\mathrm{n}=8)$.

staining analysis, the alveolar wall of the model group became thinner, and some alveolar walls were broken. There was a large amount of inflammatory cell infiltration in the interstitial space, which was consistent with the pathological features of COPD, indicating that the COPD rat model was successfully established.

Chronic inflammatory response is an important pathogenesis of COPD. A variety of inflammatory cells, cytokines and inflammatory mediators are involved in the formation of COPD. After inflammatory cells are activated, a large amount of inflammatory mediators can be released, leading to the destruction of lung structure causing emphysema, edema, and excessive secretion of mucus, airway stenosis and increased airflow resistance (17). Inflammatory mediators such as IL-6, IL-8, TNF- $\alpha$, and IL- $1 \beta$ are involved in the development of COPD, which can induce histamine release and neutrophil decomposition, promote the infiltration and release of inflammatory mediators, and induce tissue fibrosis, further aggravating lung injury (18). Dexmedetomidine is a highly selective $\alpha 2$ adrenergic receptor agonist widely used for sedation of endotracheal intubation and mechanical ventilation. Its sedative effect is very similar to the natural sleep state, which can minimize patients' stress response and has a protective effect on various organs (19). This study found that compared with the blank control group, the inflammatory mediators IL- 8 and TNF- $\alpha$ in the serum of the model control group were significantly increased, suggesting that the inflammatory response increased in the COPD rat model. After treatment with different doses of Dex, the postinflammatory mediators were significantly reduced, indicating that Dex can significantly inhibit the inflammatory response in COPD rats. This anti-inflammatory effect of Dex may be related to its control of inflammatory response and reduction of inflammatory mediators by inhibiting the excessive activation of macrophages (20).

Oxidative stress is one of the characteristics of COPD. The accumulation of oxidants in the body and the large consumption of antioxidants lead to an oxidation-antioxidation imbalance, which leads to oxidative stress and damage to lung tissue (21). Oxides in the body can cause peroxidation of lipids, resulting in a significant decrease in the fluidity of the cell membrane, causing increased permeability of the cell membrane, release of cell lysosomes, dissolution of cells, and large amounts of oxygen free radicals and aldehydes produced from peroxidation activate caspase inducing apoptosis (22). When the body's oxidative stress level is significantly increased, the body releases a large number of antioxidant enzymes such as SOD2, catalase. These antioxidant enzymes can resist oxidative stress and prevent the lungs from being damaged by oxidative stress. In this study, Dex significantly increased SOD2 and catalase proteins and the ability of scavenging oxygen free radicals, and improved ventilation and increased blood oxygen partial pressure in COPD rats. Chen et al (23) reported that Dex can reduce the synthesis of cyclic adenosine by inhibiting the activity of adenylate cyclase, thereby reducing the influx of calcium ions to the nerve endings and inhibiting the release of transmitters, then performing the anti-oxidative stress role. However, in this study, it is still unclear whether Dex directly promotes the expression of antioxidant enzymes through some regulation or Dex reduces lung oxidative stress by inhibiting 
inflammatory response, improving lung ventilation and lung oxygen supply.

Based on our study, Dex can improve oxidative stress in mechanical ventilation in rats with COPD, and can reduce lung tissue inflammation, thereby protecting lung tissue in COPD mechanically ventilated rats.

\section{Acknowledgements}

Not applicable.

\section{Funding}

No funding was received.

\section{Availability of data and materials}

The datasets used and/or analyzed during the present study are available from the corresponding author on reasonable request.

\section{Authors' contributions}

PL wrote the manuscript. PL and CS were responsible for lung histopathology test and ELISA. JH and SC contributed to the construction of the animal model. DZ performed western blot analysis. All authors read and approved the final manuscript.

\section{Ethics approval and consent to participate}

The study was approved by the Ethics Committee of the First Hospital of Qiqihar (Qiqihar, China).

\section{Patient consent for publication}

Not applicable.

\section{Competing interests}

The authors declare that they have no competing interests.

\section{References}

1. Regional COPD Working Group: COPD prevalence in 12 AsiaPacific countries and regions: Projections based on the COPD prevalence estimation model. Respirology 8: 192-198, 2003.

2. Biancardi E, Fennell M, Rawlinson W and Thomas PS: Viruses are frequently present as the infecting agent in acute exacerbations of chronic obstructive pulmonary disease in patients presenting to hospital. Intern Med J 46: 1160-1165, 2016.

3. Foschino Barbaro MP, Carpagnano GE, Spanevello A, Cagnazzo MG and Barnes PJ: Inflammation, oxidative stress and systemic effects in mild chronic obstructive pulmonary disease. Int J Immunopathol Pharmacol 20: 753-763, 2007.

4. Min T, Bodas M, Mazur S and Vij N: Critical role of proteostasisimbalance in pathogenesis of COPD and severe emphysema. J Mol Med (Berl) 89: 577-593, 2011.

5. MacNee W: Pulmonary and systemic oxidant/antioxidant imbalance in chronic obstructive pulmonary disease. Proc Am Thorac Soc 2: 50-60, 2005.
6. Amri Maleh V, Monadi M, Heidari B, Maleh PA and Bijani A: Efficiency and outcome of non-invasive versus invasive positive pressure ventilation therapy in respiratory failure due to chronic obstructive pulmonary disease. Caspian J Intern Med 7: 99-104, 2016.

7. Westhoff M, Bachmann M, Braune S, Karagiannidis C, Kluge S, Lepper PM, Müller T and Schönhofer B: Severe hypercapnic respiratory failure in acute exacerbation of COPD: Significance of ventilation and extracorporal $\mathrm{CO}_{2}$ removal. Dtsch Med Wochenschr 141: 1758-1762, 2016 (In German).

8. Hoegl S, Bachmann M, Scheiermann P, Goren I, Hofstetter C, Pfeilschifter J, Zwissler B and Muhl H: Protective properties of inhaled IL-22 in a model of ventilator-induced lung injury. Am J Respir Cell Mol Biol 44: 369-376, 2011.

9. Gu J, Chen J, Xia P, Tao G, Zhao H and Ma D: Dexmedetomidine attenuates remote lung injury induced by renal ischemia-reperfusion in mice. Acta Anaesthesiol Scand 55: 1272-1278, 2011.

10. Cosar M, Eser O, Fidan H, Sahin O, Buyukbas S, Ela Y, Yagmurca M and Ozen OA: The neuroprotective effect of dexmedetomidine in the hippocampus of rabbits after subarachnoid hemorrhage. Surg Neurol 71: 54-59, discussion 59, 2009.

11. Duffy BA, Chun KP, Ma D, Lythgoe MF and Scott RC: Dexamethasone exacerbates cerebral edema and brain injury following lithium-pilocarpine induced status epilepticus. Neurobiol Dis 63: 229-236, 2014

12. Hsing CH, Lin CF, So E, Sun DP, Chen TC, Li CF and Yeh CH: $\alpha 2$-Adrenoceptor agonist dexmedetomidine protects septic acute kidney injury through increasing BMP-7 and inhibiting HDAC2 and HDAC5. Am J Physiol Renal Physiol 303: F1443-F1453, 2012.

13. Mizutani N, Fuchikami J, Takahashi M, Nabe T, Yoshino S and Kohno S: Pulmonary emphysema induced by cigarette smoke solution and lipopolysaccharide in guinea pigs. Biol Pharm Bull 32: 1559-1564, 2009.

14. Bhatt SP, Washko GR, Dransfield MT, Sieren JC, Newell JD Jr and Hoffman EA: Comparison of spirometric thresholds in diagnosing smoking-related airflow obstruction: Authors' response. Thorax 69: 1147-1148, 2014.

15. Li G, Li J, Zhou Q, Song X, Liang H and Huang L: Growth hormone releasing peptide-2, a ghrelin agonist, attenuates lipopolysaccharide-induced acute lung injury in rats. Tohoku J Exp Med 222: 7-13, 2010.

16. Wright JL, Tai $\mathrm{H}$ and Churg A: Vasoactive mediators and pulmonary hypertension after cigarette smoke exposure in the guinea pig. J Appl Physiol (1985) 100: 672-678, 2006.

17. Zuo L, He F, Sergakis GG, Koozehchian MS, Stimpfl JN, Rong Y, Diaz PT and Best TM: Interrelated role of cigarette smoking, oxidative stress, and immune response in COPD and corresponding treatments. Am J Physiol Lung Cell Mol Physiol 307: L205-L218, 2014

18. Nie G, Xie CL, Cao YJ, Xu MM, Shi X, Zou AL and Qi JH: Meta-analysis of IL-6 -174G/C polymorphism and psoriasis risk. Genet Mol Res 15: 15, 2016.

19. Xia R, Xu J, Yin H, Wu H, Xia Z, Zhou D, Xia ZY, Zhang L, Li H and Xiao X: Intravenous infusion of dexmedetomidine combined isoflurane inhalation reduces oxidative stress and potentiates hypoxia pulmonary vasoconstriction during one-lung ventilation in patients. Mediators Inflamm 2015: 238041, 2015.

20. Callahan P, Pinto SJ, Kurland G, Cain JG, Motoyama EK and Weiner DJ: Dexmedetomidine for infant pulmonary function testing. Pediatr Pulmonol 50: 150-154, 2015.

21. Nemmar A, Raza H, Subramaniyan D, John A, Elwasila M, Ali BH and Adeghate E: Evaluation of the pulmonary effects of short-term nose-only cigarette smoke exposure in mice. Exp Biol Med (Maywood) 237: 1449-1456, 2012.

22. Kirkham PA and Barnes PJ: Oxidative stress in COPD. Chest 144: 266-273, 2013.

23. Chen J, Hou C, Chen X, Wang D, Yang P, He X, Zhou J and Li H: Protective effect of cannabidiol on hydrogen peroxide induced apoptosis, inflammation and oxidative stress in nucleus pulposus cells. Mol Med Rep 14: 2321-2327, 2016.

This work is licensed under a Creative Commons Attribution-NonCommercial-NoDerivatives 4.0 International (CC BY-NC-ND 4.0) License. 